\title{
Blending Versus Conceptual Interaction in the Construction of Illocutionary Meaning: Counterfactual Pieces of Advice ${ }^{1}$
}

\author{
Lorena Pérez Hernández \\ University of La Rioja \\ lorena.perez@dfm.unirioja.es
}

\begin{abstract}
The cognitive operation of conceptual integration or blending as described by Fauconnier and Turner $(1994,1996)$ includes the notion of emergent structure, that is to say, conceptual structure, which is part of the blend and which is independent and/or inconsistent with that of the input spaces. Emergent structure is especially noticeable in counterfactual pieces of advice of the type If I were you, I would..., which involve the construction of a mental space which is contrary-to-fact with respect to both input spaces. Nevertheless, as argued by Ruiz de Mendoza (1998), this type of blend-internal asymmetries and inconsistencies are little desirable from the point of view of cognitive economy. In connection with this observation, this paper attempts to reanalyse and explain the performance of conterfactual advising by adequately combining data from as many input spaces as necessary to yield implicated information. In doing so, our account is free from the cognitive cost which may derive from the need of making sense of independent (and contradictory) emergent structure.
\end{abstract}

\section{Introduction}

In a number of publications, Turner and Fauconnier have presented and developed the notion of conceptual integration or blending as a general, dynamic, simple cognitive operation used to construct meaning (see Fauconnier and Turner 1994, 1996, 1998; Turner and Fauconnier, 1995, 1998). Blending has been found to be pervasive in many areas of human thought. One of the central characteristics of blending is that it may develop so- 
called emergent structure, that is to say, conceptual structure which does not exist in any of the input spaces and which is only explainable in terms of the blend itself. On occasions, this emergent structure may be inconsistent with the information contained in one or more of the input spaces. This is specially noticeable in the case of counterfactual claims. Nevertheless, as argued by Ruiz de Mendoza (1996, 1997, 1998, 1999), postulating the emergence of independent and/or inconsistent structure in the blend is not desirable from the point of view of the psychological adequacy of an account of conceptual integration. Blend-internal asymmetries and inconsistencies are more costly to process in terms of cognitive economy. In an attempt to overcome this drawback of the canonical theory of blending, Ruiz de Mendoza (1998) suggests that it is possible to explain away apparently inconsistent structure by adequately combining data from as many input spaces as necessary to yield implicated information.

In connection to Ruiz de Mendoza's observation, in this paper we analyse counterfactual pieces of advice of the type If I were you, I would... Turner and Fauconnier (1998: 296) claim that an illocutionary act of this kind involves the construction of a mental space which is contrary-to-fact with respect to both input spaces. As is amply argued in section three, however, the understanding of the intended meaning of these utterances can be derived from the conceptual interaction of one or more metonymies in each the input spaces. Moreover, it is shown that this rich conceptual interaction explains the purported inconsistencies in the blend. The resulting account is free from the cognitive cost which may derive from the need of making sense of independent (and contradictory) emergent structure.

\section{Counterfactual blendings revisited}

In their paper on conceptual integration in counterfactuals, Turner and Fauconnier (1998: $288 \mathrm{ff})$ consider the following prototypical instance of counterfactual claim:

(1) If Churchill had been Prime Minister in 1938 instead of Neville Chamberlain, Hitler would have been deposed and World War II averted.

Their analysis of this counterfactual claim is carried out in terms of the many-space model of conceptual projection. As is well known, the many-space model of metaphor or theory of blending differs from the traditional two-domain model (Lakoff 1987, 1993; Lakoff and Johnson, 1980; Lakoff and Turner, 1989) in that it explains many cognitive phenomena, including metaphor and metonymy, in terms of conceptual integration of information derived from multiple mental spaces. In its most simplified form, the many-space model includes at least two input spaces (source and target) and two middle spaces (the generic space and the blended space). The generic space reflects some common abstract structure shared by the input spaces, which licenses the cross-space mapping between the source and the target. The blended space inherits partial structure from the input spaces and may also include emergent structure of its own. 
Example (1) draws information from two input spaces. The source domain, in which Churchill is seen as a politician who openly opposes German Nazism in 1938; and the target domain, where Neville Chamberlain is the Prime Minister of England who opts for a policy of appeasement, rather than one of open confrontation, towards the threat of Hitler's dictatorship in 1938. A third generic space grants the subsequent conceptual projection by reflecting structure common to both input domains: politicians holding particular opinions as to what the correct foreign policy should be in a certain country at a given point in its history. Finally, the blended space consists of partial structure projected from each of the input spaces, together with some emergent independent information developed within the blend itself. The source domain projects 'Churchill' to the blended space. From the target domain, the blend inherits the role of 'Prime Minister'. Thus, through composition, the projections from the source and the target make new relations available which didn't exit in the separate inputs: Churchill is Prime Minister in 1938. Finally, through completion and elaboration, further new structure emerges: Churchill opposes Germany's foreign policy, World War $\Pi$ is averted, and the holocaust avoided. The following figure schematises this conceptual operation:

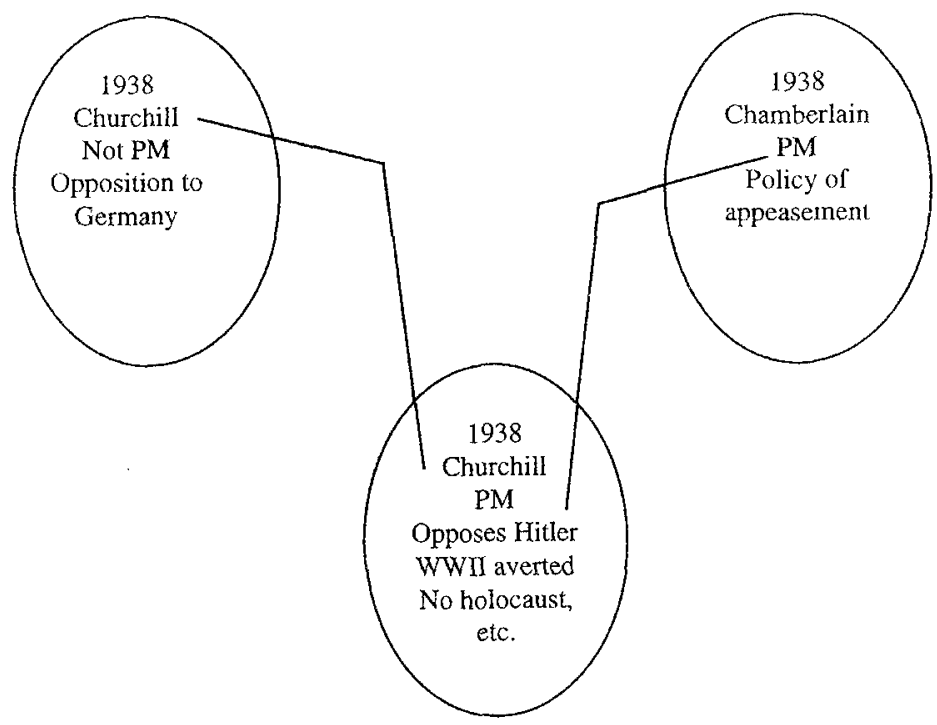

Figure 1. A many-space model account of example (1)

The resulting contrary-to-fact space displays the standard features of blending as summarised by Turner and Fauconnier (1998: 287-290). It exploits and develops counterpart connections between the two input spaces in a selective manner. The final blend 
can be input to other blends (as when Margaret Thatcher argued that just as the Allies should have refused to appease Hitler, so Western leaders should refuse to appease aggressors in the war in Bosnia) and, as shown above, it seems to develop its own emergent structure.

This counterfactual blend is impossible in reality. In spite of this, as pointed out by Turner and Fauconnier (1998: 293), the lack of analogy between the inputs revealed by the blend makes possible the effective communication of a complex reasoning, namely, the fact that dictatorships and the negative consequences they bring about can only be avoided through open confrontation. It should be noted, however, that this literal paraphrase of (1) does not have the richness of meaning of the counterfactual blend. The paraphrase does not convey the persuasive force of (1), because it is not based on previous well-known historical facts. Hence the relevance of blending as a powerful instrument of communication.

This orthodox account of blending has been recently questioned. Although the core of the theory is accepted, Ruiz de Mendoza $(1996,1997,1998,1999)$ has amply shown that there are two essential problems with Turner and Fauconnier's treatment of blended spaces. The first one is related to the claim that blends create new idiosyncratic structure of their own. Asymmetries and irregularities are not consistent with the principle of cognitive economy. Since they break the addressee's expectations in unpredictable ways, they require greater cognitive effort to be interpreted. In this connection, Ruiz de Mendoza (1997) has argued that the apparent irregularities in the resulting blends can be accounted for simply by increasing the number of input spaces involved in a projection. ${ }^{2}$ The second problem stems from the lack of attention paid to the study of the constraints which operate on conceptual projection. It is generally accepted that blending should be a principle-regulated phenomenon. Fauconnier and Turner (1998: 280) recognise the following principles underlying the process of blending:

Integration: The blend must constitute a tightly integrated scene that can be manipulated as a unit.

Web: Manipulating the blend as a unit must maintain the web of appropriate connections to the input spaces easily and without additional surveillance or computation.

Unpacking: The blend alone must enable the understander to unpack the blend to reconstruct the inputs, the cross-space mapping, the generic space, and the network of connections between all these spaces.

Topology: For any input and any element in that space projected into the blend, it is optimal for the relations of the element in the blend to match the relations of its counterpart.

Good reasons: All things being equal, if an element appears in the blend, there will be pressure to find significance for this element. Significance will include relevant links to other spaces and relevant functions in running the blend.

Some comments are in order. To begin with, it should be noted that some of these principles are in fact a posteriori attributes. Integration, web, unpacking and good reasons describe some requirements which the final blend must fulfil, but they do not specify the 
properties which the input spaces must have or the constraints which should operate on the process of blending in order for those final attributes and/or conditions to hold.

The principle of topology represents an a priori condition. It seems to be, however, a reformulation of Lakoff's $(1990,1993)$ well-known Principle of Invariance, according to which metaphoric mappings preserve the image-schematic structure of the source domain without violating the inherent structure of the target domain. Moreover, this is not the only constraint working on conceptual integration. As noted by Ruiz de Mendoza $(1996,1997)$, there are also pragmatic restrictions placed on blending. One such restrictions is the Principle of Relevance. As a result of the presumption of optimal relevance, blending operations are expected to offer the addressee the maximum number of contextual effects for the minimum processing effort. In order to achieve this, conceptual projection from the input spaces must obey at least the two following principles (Ruiz de Mendoza, 1996: 236):

1. No information which is inconsistent with either the central or any non-central intended assumption can be projected to the blend.

2. Only the minimum necessary information will be projected to the blend.

Assuming that these principles are obeyed, the hearer is entitled to consider the first acceptable interpretation of the blend as the one the speaker intends to convey.

Going back to example (1), it is now possible to offer an alternative analysis of it along these lines. The blend complies with the two principles just mentioned: only the minimum necessary information has been projected into the blend (i.e. Churchill as a Prime Minister) and no information inconsistent with the central intended assumption has been projected. This entitles the hearer to believe that the first acceptable interpretation is the intended one. Apparently, however, the projection from the two inputs creates a counter-to-reality space in which Churchill is Prime Minister in 1938, opposes Hitler, and the World War II does not take place. None of these events took place in real life at that time. Turner and Fauconnier would have argued that this is just inconsistent structure produced by the blend. Nevertheless, it is hard to imagine that we may interpret the counterfactural claim under consideration in this way. Upon hearing an utterance like (1), hearers intuitively know that the speaker is not suggesting that Churchill was once Prime Minister in a parallel world. ${ }^{3}$ What needs to be explained, therefore, is how the hearer is capable of grasping the intended meaning of that utterance, namely, that policies of open opposition are more effective that those of appeasement. I would like to argue that this interpretation is reached in two stages: (1) through a conceptual projection from two input spaces, each of which includes a further metonymic model, and (2) by means of the general inferencing capabilities of the human being operating on the resulting blend. Conceptual interaction of additional cognitive models, -metonymic models in the case that occupy us-, explains why counterfactual claims of this kind are not understood in their literal sense and, also, why, in contrast to Turner and Fauconnier's belief that the blend includes contrary-to-reality information, hearers are not puzzled by them. 
My suggestion is that the 'Churchill' and the 'Neville Chamberlain' which are mentioned in the counterfactual claim are just the source domains of two metonymies which stand for two types of politicians: those who favour open opposition and those who prefer policies of appeasement respectively. Therefore, the input spaces would be organised as follows:

INPUT 1

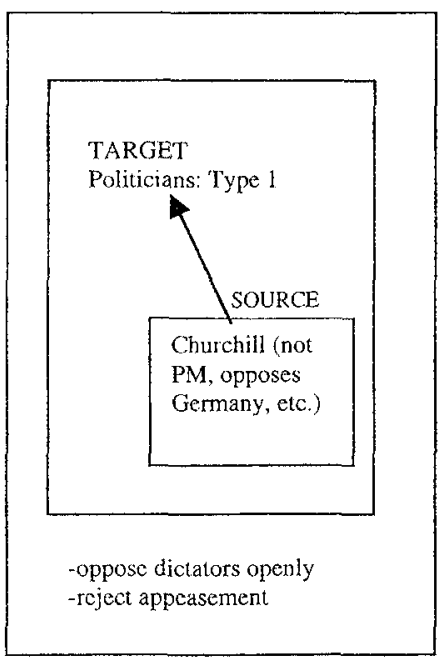

INPUT 2

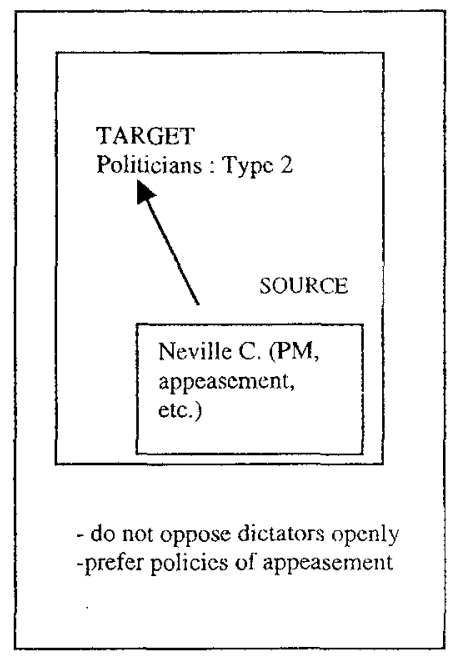

Figure 2. Metonymic mappings within input spaces

Churchill stands for those politicians who prefer open confrontation and Neville for those who would rather avoid provocation. Thus, what is being compared in the counterfactual claim is not the acting of two specific politicians, but rather two general political stances. The comparison of Churchill's and Neville's political behaviour in the situation under consideration (1938 England) would have been impossible and counter-tofact, because Churchill was not the Prime Minister at the time. The underlying metonymies, however, license the comparison of the two opposing political views represented by Churchill and Neville respectively. If this metonymic operations are taken into account, the apparent asymmetries and inconsistencies of the blend are no longer such. Moreover, since both Churchill and Neville are well-known political figures of the European history, their use as source domains of the metonymies has some advantages. From the point of view of 
cognitive economy, they activate the two types of politician straightaway. From a communicative perspective, together with the instantiation of the two kinds of politician, they bring along a wealth of rich connotations which derives from the personalities of these two statesmen (e.g. Churchill's determination and stubbornness).

The rest of the information included in the blend (i.e. the fact that World War II would not have taken place and that the holocaust would have been avoided) are reached via the addressee's general inferential ability. If the kinds of policy represented by Churchill and Neville were opposed, and if the policy represented by Neville led to a war and a holocaust, then Churchill's policy would have probably given way to the opposite outcome: no war and no holocaust.

In sum, as the alternative explanation of example (1) shows, the apparent asymmetries which emerge in the blend are far from arbitrary. They can be expected and accounted for by means of (1) a simple conceptual interaction in the form of a metonymic operation within each of the input spaces, and (2) the use of general human inferential abilities.

\section{Conceptual interaction in the understanding of counterfactual pieces of advice}

Turner and Fauconnier (1998: 296) rightly point to the ubiquity of counterfactual blends. One area of everyday reasoning and communication which makes routine and largely unnoticed use of this type of conceptual projection is that involved in giving advice. One of the most common linguistic procedures for the realization of this type of speech act takes the form of a hypothetical conditional sentence which, according to Turner and Fauconnier (1998: 296), 'requires intricate, orderly, and impressive blending to create a counterfactual space'. In the remainder of this paper, I shall analyse several instances of advising to show that their alledged counterfactuality is largely illusory. ${ }^{4}$ In doing so, it shall also become apparent that an explanation of these examples along the lines suggested in section 2 is more consistent with the principle of cognitive economy, since in this way, the seeming contradictions which emerge within the blend are accounted for as the output of simple and recurrent patterns of conceptual interaction. Our study has been carried out on a sample of a hundred instances of pieces of advice of the type If I were you... The data have been extracted from the British National Corpus.

Most instances of advising in the sample resemble example (2) below:

(2) The doctor told him: "If $I$ were you, $I$ would just pack your job".

The canonical analysis in terms of conceptual projection of this example can be schematised as follows (see next page): 

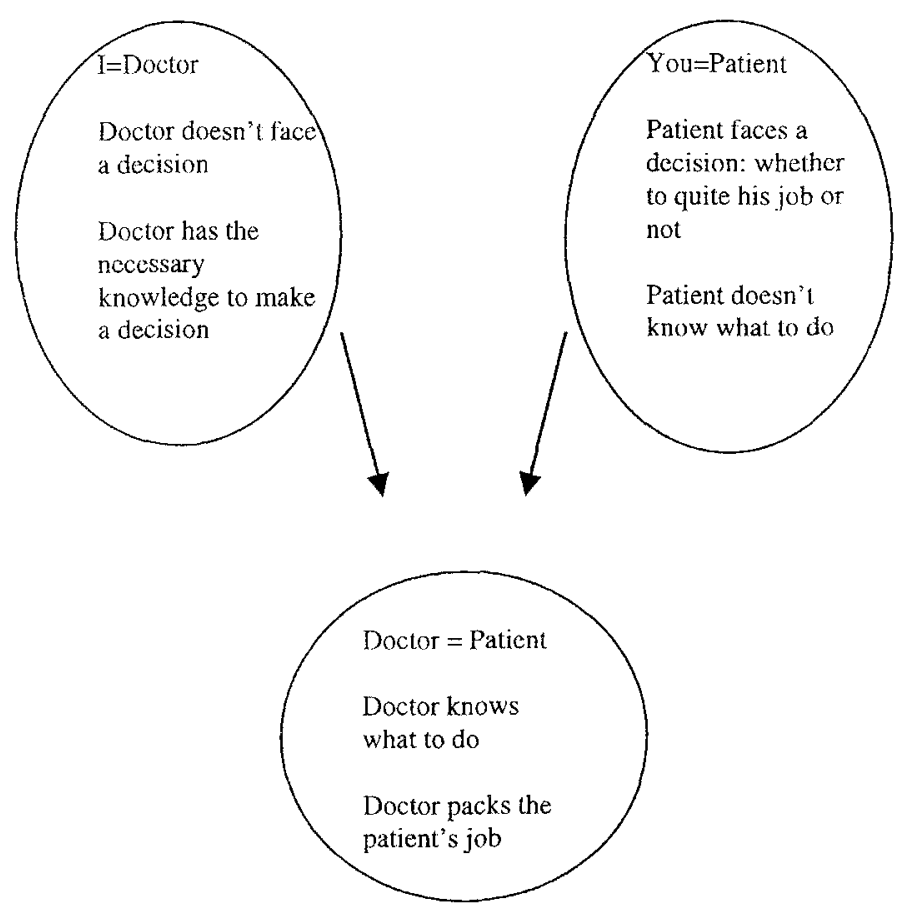

Figure 3. Schematic representation of the 'canonical' blend underlying the interpretation of example (2).

The blend creates a parallel reality which defies common sense: the doctor becomes the patient and quits the latter's job. The illusion of a counterfactual reality, however, is not so strong in an almost identical utterance like (3) below:

(3) The doctor told him: 'If $I$ were you, $I$ would just pack $m y$ job'.

The use of the first person possessive adjective in (3) hinders the creation of a counterto-fact reality. It is obvious that the speaker has not 'become' the addressee, but that he is just putting himself in the addressee's boots and considering what his course of action would be under those circumstances. The collection of data under analysis contains instances of these two types of counterfactual advice: in some cases the possessive adjectives and reflexive pronouns agree in person with the subject (I), while in others the agreement is established with the second person pronoun (you). Let us consider them in more detail: 


\section{Subject agreement}

(4) If I were you, I'd watch my step.

(5) 'Maybe not, but if I were you, Miss Williams, $I \mathrm{~d}$ make sure that $I$ confined myself to facts in future, and the most pressing one of all is the fact that someone in this town is annoyed with you!'

(6) 'Someone paid them good money, a lot of money, to do that... this so-called 'friend' they mentioned... so if I were you, I'd be trying to work out who he is rather than getting on my soapbox.'

\section{Complement agreement}

(7) And, if I were you, I wouldn't bother resting on your very dusty laurels.

(8) 'If I were you, I would hop out now while you can,' Nicola said.

(9) I shouldn't bother yourself, if I were you.

The subtle differences in the use of possessive adjective and pronoun agreement in those sentences has significant meaning consequences. Those examples which display complement agreement are perceived as more powerful and pressing pieces of advice. This obeys to the fact that, although in a kind of ambiguous way, they present the addressee as somehow involved in the carrying out of the future action. Examples (4) to (6), on the contrary, do not explicitly point to the involvement of the addressee in the predicated action.

More important, however, it is to note the fact that the existence of pieces of advice like (4) to (6) suggests that the counterfactuality of If-I-were-you advice constructions is only apparent. In processing these sentences, the addressee, of course, does not think of the speaker as actually becoming himself/herself. Let us now explain in detail the cognitive operations which underlie the interpretation of those pieces of advice and which prevent the hearer from getting trapped in a mental space packed with contradictory information.

The potential contradictions in the blend vanish simply by postulating a metonymic operation in each of the input spaces. Example (2), which is reproduced below as (10) for convenience, is analysed in this fashion (see figure four on following page):

(10) The doctor told him: 'If I were you, I would just pack your job'.

These mappings show that the expression 'If I were you...' is simply metonymically standing for 'If I were in your circumstances...' That is to say, the speaker pictures himself in the circumstances in which the addressee needs to decide on a future course of action. However, the speaker does not cease to be himself and that is why he can make use of his knowledge and make a decision (i.e. to quit working).

When subject agreement is involved, we find a similar metonymic operation which only differs from the one in figure 4 as regards the scope of the target in the second input space. 

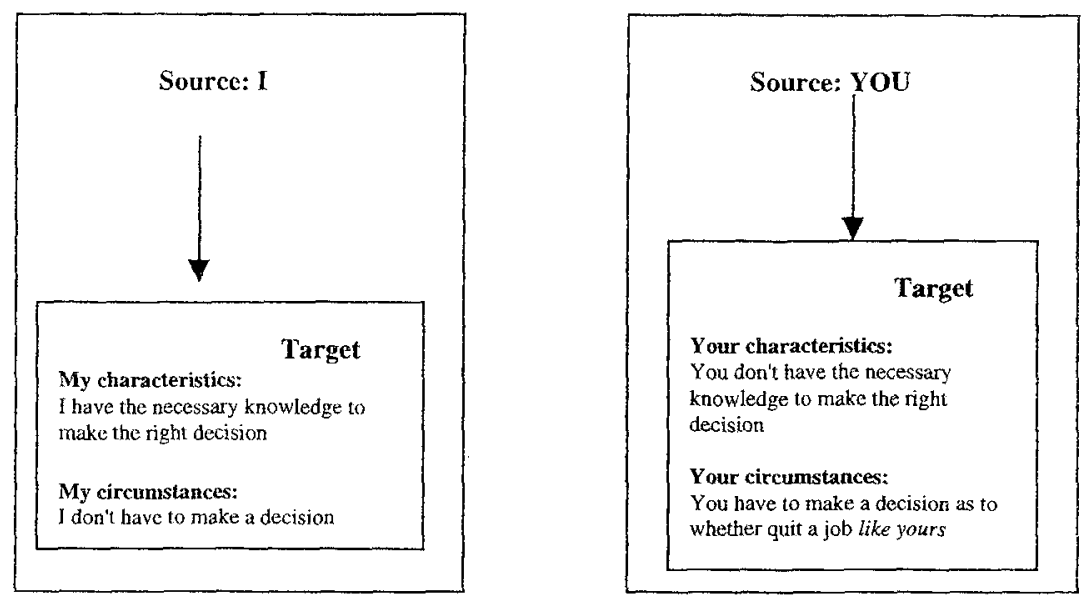

Figure 4. Conceptual interaction in the interpretation of example (10).

INPUT SPACE 1

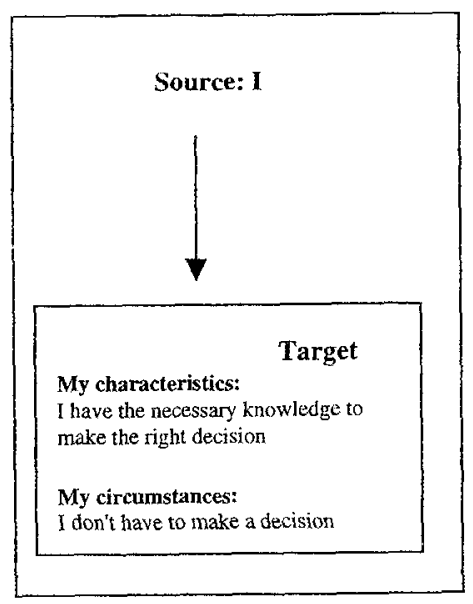

INPUT SPACE 2

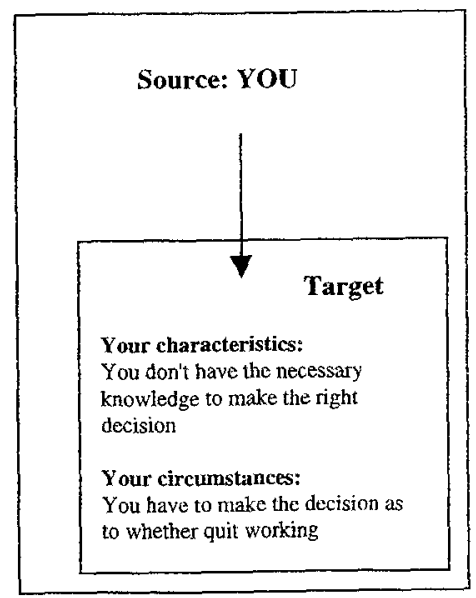

Figure 5. Metonymy underlying the interpretation of example (11) 
This is the case with example (3), which is reproduced here as (11) and which could be represented as follows (see figure five above):

(11) If I were you, I would pack $m y$ job.

While example (10) emphasises the idea of 'quitting a job of the kind of the addressee's (that specific job may be too stressful, little rewarding, etc.), in (11) the emphasis is placed on the action of just 'quitting one's job' (the addressee may be too stressed out and in need of some time to rest).

The metonymic operation described within the blended spaces of examples (10) and (11) is of the same type as those found in expressions like He is an Einstein, where Einstein is the source domain of a conceptual projection which has as its target the well-known outstanding mental abilities of the scientist:

SOURCE: Einstein

\begin{tabular}{|l|}
\hline Grey hair \\
Wears glasses \\
Has moustache \\
TARGET \\
outstandingly intelligent
\end{tabular}

Figure 6. Underlying metonymic mapping in the expression He is an Einstein

Further evidence against positing the creation of a counterfactual reality, as Turner and Fauconnier do, in these cases of advising comes from examples like number (12) below:

(12) 'It's his land. But if I were you both, I wouldn't disturb the dead, very dangerous!'

The use of the plural emphatic pronoun you both precludes the building of a parallel reality, since a situation in which the speaker is transformed into two different people at the same time is even more difficult to imagine. In contrast, two metonymic mappings like those proposed for examples (10) and (11), in which the speaker stands for his own circumstances and the addressees stand for theirs, leads to the correct understanding that the speaker has not been transformed into anyone, but that he is just putting himself in someone else's shoes. 
Let us finish this discussion on the role of conceptual interaction in the interpretation of the illocutionary act of advising by considering the following puzzling example:

(13) If I were you, I'd get in touch with me if something turned up. In a situation of that kind, you'd need someone who can keep a secret.

If the previous analysis of examples (10) and (11) is applied to this utterance, we may paraphrase it like this: If I were in a situation like the one you are facing, I would get in touch with me if something turned up. Still, the utterance does not make sense. What is the point in 'me getting in touch with myself' in order to solve a problem? Our knowledge about prototypical human behaviour tells us that, if one is in trouble, one usually asks someone else for help. Nevertheless, the sentence can be made sense of by positing a double metonymic mapping: the first person pronoun $m e$ is the source domain of a metonymy in which the speaker makes himself stand for some of his attributes, namely, the fact that he is a trustworthy, reliable person. In turn, these attributes stand for the whole class of people who have such features:

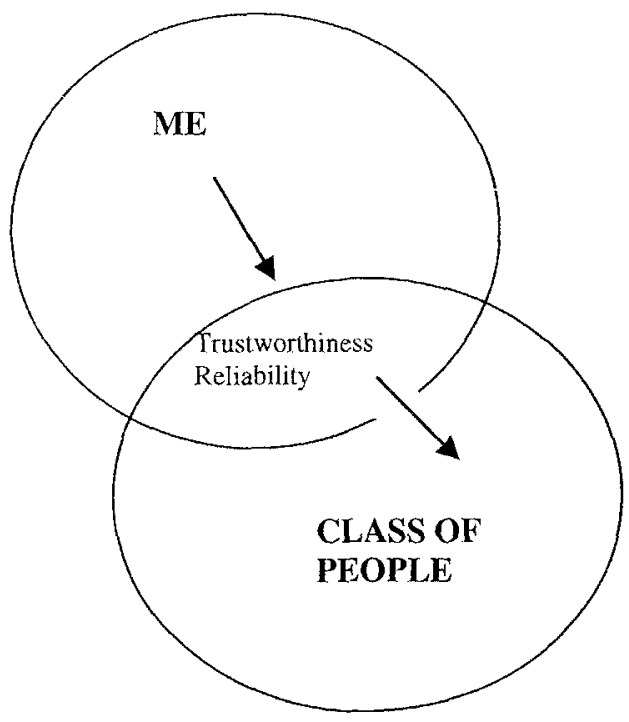

Figure 7. Double Metonymic mapping underlying example (13)

In this way, the addressee is capable of grasping the intended meaning: If I were in a situation like the one you are facing, I would get in touch with someone like me (i.e. a member of the trustworthy, reliable class of people) if something turned up. 


\section{Conclusions}

In the present paper, I have argued against positing the existence of inconsistent emergent structure in blended spaces in the specific case of so-called counterfactual advising. I have shown that the apparent contradictions that have been attributed to counterfactual claims of this kind can be made sense of simply by developing the structure of the input or blended spaces involved. More specifically, it has been contended that the metonymic mappings which operate within those mental spaces lie at basis of the understanding of these illocutionary acts. In addition, as has been illustrated, these recurrent metonymic operations explain the fact that speakers are not puzzled by the apparent contradictions which are associated with counterfactual claims. Since speakers do not need to invest any time or cognitive effort in disentangling blend-internal asymmetries and inconsistencies, the present refinement of the canonical theory of blending represents a step forward towards the achievement of an optimal degree of psychological adequacy.

\section{Notes}

1. Financial support for this research has been given by the DGES, grant no. BFF2000-0934, Ministry of Education and Culture, Spain.

2. Ruiz de Mendoza $(1996,1997,1998,1999)$ has reanalysed some of Turner and Fauconnier's most well-known examples of blending to show that inconsistencies are not such. They can be made sense of either as contextual implications or as the output of more complex cognitive operations involving a greater number of cognitive models. Example (1) is analysed below in this fashion.

3. It should be taken into account that in the example under consideration, the illusion of the existence of a counterfactual parallel reality is aided by the fact that Churchill and Neville both lived during the same time span, and therefore, Churchill actually had a real chance at that time to have become the Prime Minister instead of Neville Chamberlain. An utterance like If I had been Julius Caesar, the Gaulles would have never been conquered, where it is obvious that I was never and could have never been Julius Caesar, on the contrary, does not lead to the creation of a counterfactual reality so straightforwardly.

4. This study has been carried out on a sample of a hundred instances of pieces of advice of the type If I were you... The data have been extracted from the British National Corpus.

\section{Works cited}

Fauconnier, Guiles and Mark Turner (1994): Conceptual Projection and Middle Spaces. UCSD: Department of Cognitive Science Technical Report 9401.

. (1996): "Blending as a Central Process of Grammar". In A. Goldberg, ed., Conceptual Structure, Discourse, and Language. Stanford: Center for the Study of Language and Information.

(1998): "Principles of Conceptual Integration". In J-P. Koenig, ed., Discourse and Cognition. Gridging the Gap. Stanford, California: CSLI Publications, 269-283. 
Lakoff, George and Mark Johnson (1980): Metaphors we live by. Chicago, IL: University of Chicago Press.

Lakoff, George and Mark Turner (1989): More than cool reason. A field guide to poetic metaphor. Chicago, IL: University of Chicago Press.

Lakoff, George (1987): Women, Fire, and Dangerous Things. What Categories Reveal About the Mind. Chicago: University of Chicago Press.

. (1990): "The Invariance Hypothesis: is abstract reason based on image-schemas?" Cognitive Linguistics 1-1: 39-74.

(1993): "The contemporary theory of metaphor". In A. Ortony, ed., Metaphor and Thought. Cambridge: Cambridge University Press, 202-251.

Ruiz de Mendoza Ibáñez, Francisco J. (1996): "Blended Spaces and the Pragmatic Approach to Cognition". In B. Penas, ed., The Intertextual Dimension of Discourse. Universidad de Zaragoza, 233-244.

. (1997): "Metaphor, metonymy, and conceptual interaction". Atlantis, Journal of the Spanish Association for Anglo-American Studies 19(1): 281-295.

. (1998): "On the nature of blending as a cognitive phenomenon". Journal of Pragmatics, $30,3: 259-274$.

(1999): "From Semantic Underdetermination Via Metaphor and Metonymy to Conceptual Interaction". LAUD. Linguistic Agency. Paper $\mathrm{n}^{\circ}$ 492. Essen: Universität Gesamthocschule Essen.

The British National Corpus. 1991. Oxford University Press, Longman, Chambers-Larousse, Oxford University Press, Lancaster University and British Library. [Available on-line from http://info.ox.ac.uk/bnc/]

Turner, Mark and Guiles Fauconnier (1995): "Blending and metaphor". In Shen and Kasher, eds., Cognitive Aspects of Metaphor. London: Routledge.

. (1998): "Conceptual Integration in Counterfactuals". In J-P. Koenig, ed., Discourse and Cognition. Gridging the Gap. Stanford, California: CSLI Publications, 285-296. 